\title{
An overview of the LOess Plateau mesa region land surface process field EXperiment series (LOPEXs)
}

\author{
J. Wen, L. Wang, and Z. G. Wei \\ Key Laboratory for Climate-Environment and Disasters of Western China, Cold and Arid Regions Environmental and \\ Engineering Research Institute, Chinese Academy of Sciences, Lanzhou, Gansu 730000, China
}

Received: 19 January 2009 - Published in Hydrol. Earth Syst. Sci. Discuss.: 24 February 2009

Revised: 27 May 2009 - Accepted: 29 May 2009 - Published: 29 June 2009

\begin{abstract}
A series of land surface process field experiments were carried out in a mesa region of the Chinese Loess Plateau in each of the years from 2004 to 2008 (acronymized as LOPEX04, LOPEX08, etc.). The general objectives of this series of experiments, observational data sets, and preliminary science results are presented in this paper. The prospective research topics by using the LOPEXs data sets are discussed.
\end{abstract}

\section{Introduction}

The Chinese Loess Plateau, along the middle reaches of the Yellow River, has complex geomorphic landscapes. With elevations ranging from several hundreds to two thousands meters, it consists of diverse landscapes including the loess mesa, lowland, gully, hill, loess ridge, continuous knoll, dry gulch, flat ground, loess terrace and other land surface types (Yang and Shao, 2000). The loess deposition, which is the main ingredient of the local soil, is loose and easily washed away by runoff. Thus the Yellow River with the tremendous levels of silt anywhere in its reaches flows through this region and carries away more than 1.4 billions tons of silt annually, with about $430000 \mathrm{~km}^{2}$ area suffering from serious soil erosion (Zhang and Lu, 2000). Therefore, the nowadays national policy of Chinese government, "Abandoning Sterile Mountainous Farming Areas for Growing Trees or Grass", is a necessary and strategic measure to meliorate the environment over these kinds of land surfaces.

Among these various loess plateau landscapes, the loess mesa is characterized by a large flat area at mountain top,

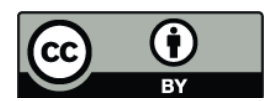

Correspondence to: J. Wen

(jwen@lzb.ac.cn) where agriculture has been well developed and has been supporting one-twelfth of the Chinese population (Qian, 1991). Many land surface process studies have been conducted worldwide (Gao et al., 2003; Ma, 2004; Vernekar et al., 2002; Yang et al., 2004), of which few is on the loess plateau because of its complex underlying surface. However, a land surface process study in this loess mesa region would be a significant contribution to understanding the characteristics of land surface energy balance, land surface parameterization, water cycle, and soil conservation over the Chinese Loess Plateau. Based on these motivations, we have organized field experiments series from 2004 to 2008 . The period and focus of each LOPEX are listed in Table 1.

A long term monitoring of the land-atmosphere energy and water exchange is essential for assessing the climate change, validating or improving upon the existing surface flux parameterization schemes in various weather forecast models and other applications. However, the eddy covariance measurement system which needs to be carefully maintained, and it is not adequate for this task. Therefore, the boundary layer meteorology tower at the LOPEXs central station was modified from original 2-levels to 5-levels $(1 \mathrm{~m}, 2 \mathrm{~m}, 4 \mathrm{~m}, 8 \mathrm{~m}$ and $16 \mathrm{~m}$ ) for measurements of wind speed and direction, air temperature and humidity. A solar radiation quantum sensor (LI190SB, LI-COR, USA) was mounted at $3.0 \mathrm{~m}$ height. All these equipments are to be deployed for long term monitoring of the land surface process over the Loess Plateau land surface process, which is one of the focuses of the LOPEX08 researches and thereafter projects.

The general objectives of these field campaign series are to measure the land surface energy components, soil temperature, soil moisture, and to collect ground measurements for validation of satellite remote sensing observation of the land surface process. 
Table 1. The measurement variables, observational period and their relevant information.

\begin{tabular}{|c|c|c|c|c|c|c|}
\hline Name & Eddy Covariance System & PBL Tower & Others & Time period & Focuses & Remarks \\
\hline LOPEX04 & $\begin{array}{l}\text { 3-D wind fluctuation }(3 \mathrm{~m}) \\
\mathrm{H}_{2} \mathrm{O} \text { vapor fluctuation }(3 \mathrm{~m}) \\
\text { Net radiation }(1.5 \mathrm{~m}) \\
\text { Soil heat flux }(-10 \mathrm{~cm} \text { and }-20 \mathrm{~cm}) \\
\text { Soil temperature \& moisture }(-5 \mathrm{~cm} \text {, } \\
-10 \mathrm{~cm},-20 \mathrm{~cm} \text { and }-40 \mathrm{~cm})\end{array}$ & $\begin{array}{l}\text { Wind speed }(4 \mathrm{~m}) \\
\text { Air temperature and humidity }(2 \mathrm{~m}) \\
\text { Net radiation }(1.5 \mathrm{~m}) \\
\text { Soil heat flux }(-10 \mathrm{~cm} \text { and }-20 \mathrm{~cm}) \\
\text { Soil temperature \& moisture }(-5 \mathrm{~cm} \text {, } \\
-10 \mathrm{~cm},-20 \mathrm{~cm} \text { and }-40 \mathrm{~cm})\end{array}$ & $\begin{array}{l}1 \mathrm{EC} \text { site was cornfield } \\
\text { on the mesa } \\
1 \mathrm{EC} \text { site was fallow on } \\
\text { the floor of the mesa }\end{array}$ & $\begin{array}{l}\text { EC: } 2004.08 .25- \\
2004.09 .12 \\
\text { PBL: } 2004.08 .25- \\
2004.12 .31\end{array}$ & $\begin{array}{l}\text { Pilot experiment for } \\
\text { exploring the possibility } \\
\text { to conduct the Loess } \\
\text { Plateau land surface } \\
\text { process field experiment }\end{array}$ & $\begin{array}{l}1 \text { set of EC shared } \\
\text { the measurements of } \\
\text { net radiation,soil } \\
\text { heat flux, soil } \\
\text { temperature and } \\
\text { moisture with PBL tower }\end{array}$ \\
\hline LOPEX05 & $\begin{array}{l}\text { 3-D wind fluctuation }(3 \mathrm{~m}) \\
\mathrm{H}_{2} \mathrm{O} \text { vapor fluctuation }(3 \mathrm{~m}) \\
\text { Net radiation }(1.5 \mathrm{~m}) \\
\text { Soil heat flux }(-10 \mathrm{~cm} \text { and }-20 \mathrm{~cm}) \\
\text { Soil temperature \& moisture }(-5 \mathrm{~cm} \text {, } \\
-10 \mathrm{~cm},-20 \mathrm{~cm} \text { and }-40 \mathrm{~cm})\end{array}$ & $\begin{array}{l}\text { Wind speed }(10 \mathrm{~m}) \\
\text { Air temperature and humidity }(3 \mathrm{~m}) \\
\text { Net radiation }(1.5 \mathrm{~m}) \\
\text { Soil heat flux }(-10 \mathrm{~cm} \text { and }-20 \mathrm{~cm}) \\
\text { Soil temperature \& moisture }(-5 \mathrm{~cm} \text {, } \\
-10 \mathrm{~cm},-20 \mathrm{~cm} \text { and }-40 \mathrm{~cm})\end{array}$ & $\begin{array}{l}1 \text { EC site was cornfield } \\
\text { on the mesa } \\
1 \text { EC site was fallow } \\
\text { on the mesa } \\
1 \text { EC site was cornfield } \\
\text { on the floor of the mesa }\end{array}$ & $\begin{array}{l}\text { EC: } 2005.7 .12- \\
2005.09 .03 \\
\text { PBL: } 2005.01 .01- \\
2005.12 .31\end{array}$ & $\begin{array}{l}\text { Determination of the land } \\
\text { surface process } \\
\text { characteristics and } \\
\text { development of satellite } \\
\text { remote sensing } \\
\text { algorithm. }\end{array}$ & $\begin{array}{l}1 \text { set of EC shared } \\
\text { the measurements of } \\
\text { net radiation, soil } \\
\text { heat flux, soil } \\
\text { temperature \& } \\
\text { moisture with PBL tower }\end{array}$ \\
\hline LOPEX06 & $\begin{array}{l}\text { 3-D wind fluctuation }(3 \mathrm{~m}) \\
\mathrm{H}_{2} \mathrm{O} \text { vapor fluctuation }(3 \mathrm{~m}) \\
\text { Net radiation }(1.5 \mathrm{~m}) \\
\text { Soil heat flux }(-10 \mathrm{~cm} \text { and }-20 \mathrm{~cm}) \\
\text { Soil temperature \& moisture }(-5 \mathrm{~cm} \text {, } \\
-10 \mathrm{~cm},-20 \mathrm{~cm} \text { and }-40 \mathrm{~cm})\end{array}$ & $\begin{array}{l}\text { Wind speed }(10 \mathrm{~m}) \\
\text { Air temperature and humidity }(3 \mathrm{~m}) \\
\text { Net radiation }(1.5 \mathrm{~m}) \\
\text { Soil heat flux }(-10 \mathrm{~cm} \text { and }-20 \mathrm{~cm}) \\
\text { Soil temperature \& moisture }(-5 \mathrm{~cm} \text {, } \\
-10 \mathrm{~cm},-20 \mathrm{~cm} \text { and }-40 \mathrm{~cm})\end{array}$ & $\begin{array}{l}1 \text { EC site was cornfield } \\
\text { on the mesa } \\
1 \text { EC site was millet } \\
\text { on the mesa }\end{array}$ & $\begin{array}{l}\text { EC: } 2006.04 .15- \\
2006.06 .15 \\
\text { PBL: } 2006.01 .01- \\
2006.12 .31\end{array}$ & $\begin{array}{l}\text { Assessing of the Loess } \\
\text { Plateau land surface } \\
\text { process during the } \\
\text { growing season and } \\
\text { atmospheric boundary- } \\
\text { layer sounding }\end{array}$ & $\begin{array}{l}1 \text { set of EC shared } \\
\text { the measurements of } \\
\text { net radiation, soil } \\
\text { heat flux, soil } \\
\text { temperature \& } \\
\text { moisture with PBL tower }\end{array}$ \\
\hline LOPEX07 & $\begin{array}{l}3 \text {-D wind fluctuation }(3 \mathrm{~m}) \\
\mathrm{H}_{2} \mathrm{O} \text { vapor fluctuation }(3 \mathrm{~m}) \\
\text { Net radiation }(1.5 \mathrm{~m}) \\
\text { Soil heat flux }(-10 \mathrm{~cm} \text { and }-20 \mathrm{~cm}) \\
\text { Soil temperature \& moisture }(-5 \mathrm{~cm} \text {, } \\
-10 \mathrm{~cm},-20 \mathrm{~cm} \text { and }-40 \mathrm{~cm})\end{array}$ & $\begin{array}{l}\text { Wind speed }(10 \mathrm{~m}) \\
\text { Air temperature and humidity }(3 \mathrm{~m}) \\
\text { Net radiation }(1.5 \mathrm{~m}) \\
\text { Soil heat flux }(-10 \mathrm{~cm} \text { and }-20 \mathrm{~cm}) \\
\text { Soil temperature \& moisture }(-5 \mathrm{~cm} \text {, } \\
-10 \mathrm{~cm},-20 \mathrm{~cm} \text { and }-40 \mathrm{~cm})\end{array}$ & $\begin{array}{l}\text { The EC site was wheat } \\
\text { field on the mesa }\end{array}$ & $\begin{array}{l}\text { EC: } 2007.8 .24- \\
2007.9 .11 \\
\text { PBL: } 2007.01 .01- \\
2007.12 .31\end{array}$ & $\begin{array}{l}\text { Evaluation of land } \\
\text { surface carbon cycle over } \\
\text { the Loess Plateau mesa } \\
\text { region. }\end{array}$ & $\begin{array}{l}\mathrm{CS}-7500 \text { was } \\
\text { deployed to measure } \\
\mathrm{H}_{2} \mathrm{O} / \mathrm{CO}_{2} \text { fluctuation } \\
\text { instead of } \mathrm{KH}_{2} \mathrm{O}\end{array}$ \\
\hline LOPEX08 & $\begin{array}{l}\text { 3-D wind fluctuation }(3 \mathrm{~m}) \\
\mathrm{H}_{2} \mathrm{O} \text { vapor fluctuation }(3 \mathrm{~m}) \\
\text { Net radiation }(1.5 \mathrm{~m}) \\
\text { Soil heat flux }(-10 \mathrm{~cm} \text { and }-20 \mathrm{~cm}) \\
\text { Soil temperature \& moisture }(-5 \mathrm{~cm} \text {, } \\
-10 \mathrm{~cm},-20 \mathrm{~cm} \text { and }-40 \mathrm{~cm})\end{array}$ & $\begin{array}{l}\text { Wind speed }(1 \mathrm{~m}, 2 \mathrm{~m}, 4 \mathrm{~m}, 8 \mathrm{~m}, 16 \mathrm{~m}) \\
\text { Air temperature and humidity } \\
(1 \mathrm{~m}, 2 \mathrm{~m}, 4 \mathrm{~m}, 8 \mathrm{~m}, 16 \mathrm{~m}) \\
\text { Net radiation }(1.5 \mathrm{~m}) \\
\text { Soil heat flux }(-10 \mathrm{~cm} \text { and }-20 \mathrm{~cm}) \\
\text { Soil temperature \& moisture }(-5 \mathrm{~cm} \text {, } \\
-10 \mathrm{~cm},-20 \mathrm{~cm} \text { and }-40 \mathrm{~cm})\end{array}$ & $\begin{array}{l}\text { The EC site was wheat } \\
\text { field on the mesa }\end{array}$ & $\begin{array}{l}\text { EC: } 2008.04 .15- \\
2008.05 .15 \\
\text { PBL: } 2008.5 .21- \\
2008.12 .31\end{array}$ & $\begin{array}{l}\text { Inter-comparison of the } \\
\text { eddy covariance flux } \\
\text { systems and the } \\
\text { boundary-layer } \\
\text { meteorology tower } \\
\text { measurements. }\end{array}$ & $\begin{array}{l}\text { The sensors and } \\
\text { specifications of } \\
\text { wind and air } \\
\text { temperature and } \\
\text { humidity were the same } \\
\text { as LOPEX07 before } \\
\text { May 21, } 2008 \text {. }\end{array}$ \\
\hline
\end{tabular}

\section{Descriptions of the experiment and datasets}

The LOPEX series were conducted in the Chinese Loess Plateau mesa region, near Pingliang city, Gansu province of China as shown in Fig. 1. The experiment area, the Baimiao mesa cornfield, millet field, fallow and its adjacent lowland cornfield or fallow. The coordinates of the central point are $106.4^{\circ} \mathrm{E}, 35.3^{\circ} \mathrm{N}$ with a $1592.0 \mathrm{~m}$ elevation above sea level.

The experimental area is located in a semiarid climate zone with an annual mean air temperature of $6.0^{\circ} \mathrm{C}$. The maximum-recorded air temperature is $34.0^{\circ} \mathrm{C}$ and the lowestrecorded air temperature is $-24.0^{\circ} \mathrm{C}$. The average annual precipitation is about $510.0 \mathrm{~mm}$. There are $2425.0 \mathrm{~h}$ of sunshine per year and 170 days free of frost (Wei et al., 2005). Representative soil types in the Loess Plateau include heavy loam, medium loam, light loam, and sandy loam.

Many land surface process field experiments had been conducted in the Tibet Plateau, the Northwest China arid region of and the Northern China plain. However, there are few researches addressing the land surface process over the Loess plateau because of its complicated terrain and landscapes. In order to explore the feasibility to conduct a land surface process field experiment in the Loess Plateau mesa region, the LOPEX04 was conducted during the period from 25 August to 12 September, 2004. Two sets of eddy covariance flux measurement systems were set up at a cropland and fallow

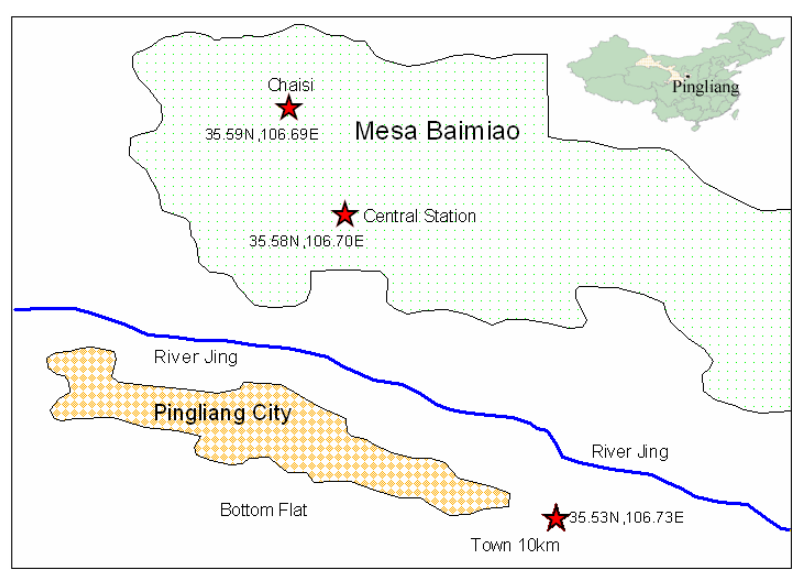

Fig. 1. The location of the LOess Plateau Mesa Region Land Surface Process Field Experiment series (LOPEXs) observation sites.

fields both near the LOPEX central station. The results show that the general characteristics of the Loess Plateau land surface process are similar to that of other landscapes, but the land surface imbalance and energy storage are quit different. Such as the land surface energy balance is lower than that measured in other regions (Wen et al., 2007). The difference between the land-atmosphere energy and water exchanges 
over the crop field and fallow are large. Consequently, these issues raised the coming research topics for the subsequent LOPEXs activities.

In 2005, three sets of eddy covariance flux measurement systems were deployed during the experimental period. One was set up at the fallow field at the low farmland. The other two were set up on the mesa regions characterized by millet and corn fields. The sensible heat flux, latent heat fluxes could be derived from these measurements. The net radiation fluxes were derived from the observation of three Kipp \& Zonen CRN-1 radiometer systems installed at three sites.

Soil heat flux was measured by using heat transducers (HFT01) at $2.5 \mathrm{~cm}$ and $10 \mathrm{~cm}$ depths. Soil volumetric water content and soil temperature were measured at $2.5 \mathrm{~cm}$, $10 \mathrm{~cm}, 20 \mathrm{~cm}$ and $40 \mathrm{~cm}$ depths using four Model 107 and four CS616 TDR probes. Surface roughness for the soil moisture estimates from satellite microwave remote sensing measurements was also measured at different sites. In addition, an Automatic Weather Station (AWS) was installed at the southern edge of the mesa for monitoring mountainvalley winds; the measurements included wind velocity and direction at $2.0 \mathrm{~m}$ height, and temperature and humidity at $1.5 \mathrm{~m}$ height during the experimental period. The new findings of the LOPEX05 were that the contributions from storage term of the atmosphere-canopy layer between the Sonic Anemometer and land surface, and the soil layer between land surface and the level where the heat flux panel was buried to the energy closure was about $11.0 \%$ and $3.0 \%$ (Liu et al., 2007); the evaportranspiration was a main way that the loess lost its water into the local air (Liu et al., 2008).

The LOPEX05 collected a large amount of land surface process field experiment datasets, but the measurements in terms of the land-atmosphere interaction during the crop growing season was not involved because the structure of the Loess Plateau meteorology boundary-layer was not sounded. To bridge this shortage, LOPEX06 was conducted for the eddy covariance flux measurement systems at wheat and benne fields. In addition, a 15-day's tether-balloon probing was also conducted for exploring the Loess Plateau atmospheric boundary-layer structure during the LOPEX06 period (Wei et al., 2009). The new findings of the LOPEX06 were that the loess water deficits were different at different temporal scale (Wang et al., 2009); the Loess Plateau meteorology boundary-layer could reach $15000 \mathrm{~m}$ height (Wei et al., 2009).

The LOPEX07 was conducted for measuring $\mathrm{CO}_{2}$ flux over the Loess Plateau mesa region with a $\mathrm{CO}_{2} / \mathrm{H}_{2} \mathrm{O}$ Open Path Gas Analyser (CS7500, Campbell, Inc. USA). The maximum and minimal land-atmosphere $\mathrm{CO}_{2}$ exchange fluxes are $0.06 \mathrm{mg} \mathrm{m}^{-2} \mathrm{~s}^{-1}$ and $0.21 \mathrm{mg} \mathrm{m}^{-2} \mathrm{~s}^{-1}$ on average, the results was similar to that observed in Inner Mongolian grassland (Liu et al., 2008).

The two key focuses of the LOPEX08 were 5-lelve wind, temperature and humidity observations for long term land surface process monitoring and inter-comparison of land surface process assessed from the eddy covariance flux measurement systems and the boundary-layer meteorology tower measurements. We found that the measurement of a boundary-layer meteorology tower was essential for longterm monitoring and research of the land surface process.

Daily values of soil moisture, temperature, salinity and soil water conductivity were measured using a Hydro-probe sensor (Stevens Water Monitoring Systems, Inc. USA) at each site during LOPEX05. Soil gravity moisture samplings were conducted at the same time for validations of the algorithm developed for soil moisture estimates from satellite microwave remote sensing data. Vegetation leaf area index, vegetation water content and height were measured at some sites too. The satellite remote sensing technique is useful in land surface process study ( $\mathrm{Su}, 2002$; Wen et al., 2003; Ma, 2004; Liu et al., 2007), satellite remote sensing data including ENVIronment SATellite/Advanced Synthetic Aperture Radar (ENVISAT/ASAR), ENVIronment SATellite/Medium Resolution Imaging Spectrometer (ENVISAT/MERIS), ENVIronment SATellite/Advanced Along-Track Scanning Radiometer (ENVISAT/AASTR), Terra/Moderate Resolution Imaging Spectroradiometer (Terra/MODIS) or Aqua/Moderate Resolution Imaging Spectroradiometer (Aqua/MODIS), LANDSAT Satellite/Thematic Mapper (Landsat/TM) have been collected for testing the algorithm that are developed for estimating land surface variables and applied in the Chinese Loess mesa region.

\section{Preliminary results}

Three sets of eddy covariance flux measuring systems were set up at three sites separately during LOPEX05 period. Figure 1 shows the site locations denoted by pentacles. To make the experimental measurement data comparable and reliable, three eddy covariance flux measurement systems were set up at the same field for one to two days' inter-comparison observation prior to and after the experiment (Wen et al., 2007).

The time series of the land surface energy balance indicated that the degree of energy imbalance is considerable in the loess plateau Soil-Plant-Atmosphere Continuum (SPAC) system, especially during daytime. The soil heat flux plays an important role in land surface energy balance, which implies that the magnitudes of heat storage terms for the soil, vegetation canopy, and near surface air layer are also considerable in the loess mesa SPAC system. Detailed measurements of soil temperature, soil moisture, canopy temperature and air temperature are necessary for estimating these storage terms in the land surface energy balance study (Meyers and Hollinger, 2004). This phenomenon also occurred during LOPEX05 period. Figure 2 presents a result of the Loess Plateau land surface energy balance without or with considering energy storage terms. It is shown that the surface 

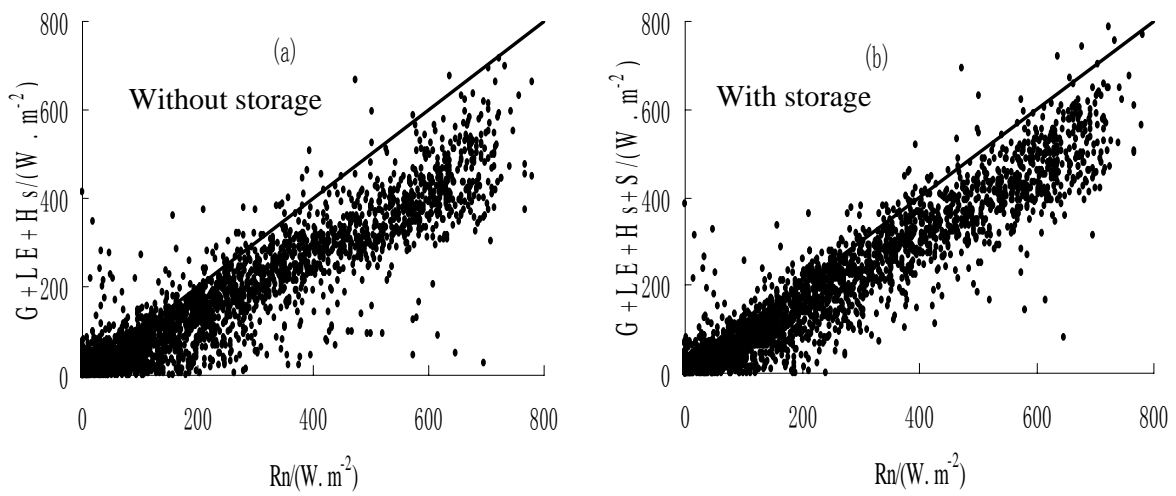

Fig. 2. The Land surface energy balance during the LOPEX05. (a) The net radiation to the sum of sensible, latent and ground heat fluxes, (b) The net radiation to the sum of sensible, latent, ground heat and total storage fluxes.
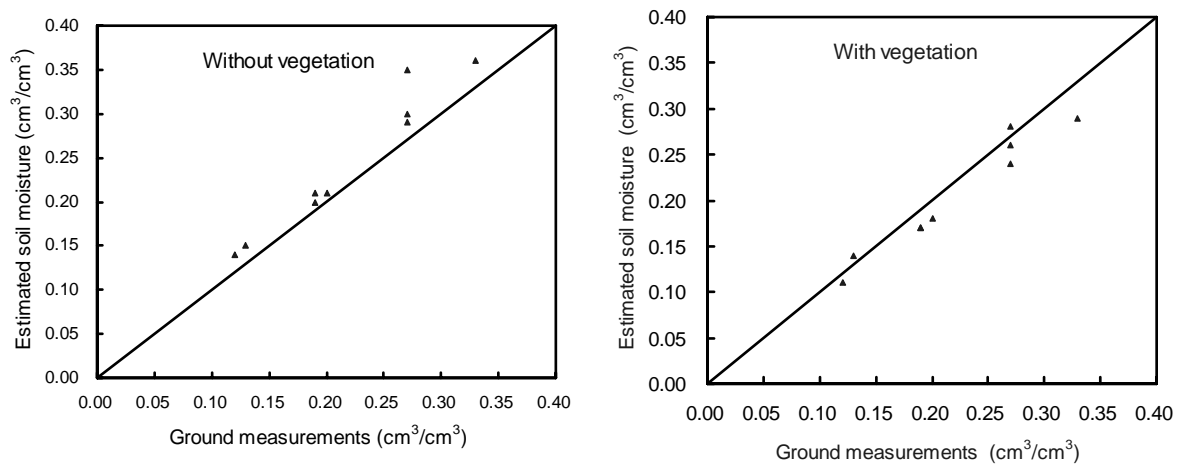

Fig. 3. The regional soil moisture distribution retrieved from ENVISAT/ASAR data and its validation over LOPEX study area.

energy closure is evidently improved with consideration of energy storage terms (Liu et al., 2007).

The ENVISAT/ASAR image indicated that the landscapes of the experiment areas are very complicated and rugged, but the main features of the experiment area could be still identified. The satellite remote sensing retrieved regional soil moisture and its validation over the study area are presented in Fig. 3. The results show that the regional variation of the retrieved soil moisture and vegetation water content are large and the satellite remote sensing estimated soil moisture and vegetation water content are in good agreement with the field experimental measurements (Zhang et al., 2009).

The ground samples of surface moisture range from 4.2 to $22.7 \mathrm{~g} / \mathrm{cm}^{3}$ for gravimetric soil moisture and $5.7-38.7 \%$ for volumetric soil moisture. The soil moisture responses to local rainfall event evidently, and the fluctuation of soil moisture is large for topsoil. The leaf area index ranged from 2.6 to 5.3 for corn and 1.9-4.7 for millet, and vegetation water content is ranged from 4.9 to $10.9 \mathrm{~kg} / \mathrm{m}^{2}$ for corn and 0.4 to $4.4 \mathrm{~kg} / \mathrm{m}^{2}$ during the LOPEX05 experimental period. The other data are still being processed and analyzed.
Understanding the structure of atmospheric boundarylayer is essential to the land surface process study over the Loess Plateau, but little atmosphere boundary layer meteorology probing has been conducted there till now. LOPEX06 arranged a 15-days, atmospheric boundary-layer profile probing (once per three hours if the weather condition was permitted). The results show that the lower atmosphere variation is controlled by near surface layer, and the upper atmospheric property is controlled by west wind belt. The boundary-layer height is about $1100 \mathrm{~m}$ over the LOPEX study area at 16:00 BT, 25 August 2006 (Wei et al., 2009).

To simulate water and heat transfer in cropped field experiments on the Loess Plateau, the water and heat transfer equations are solved by an iterative Newton-Raphson technique and a finite difference method is used to solve the governing equations. The simulated temporal variation of the soil water content and soil temperature were validated by the ground measurement data collected during the LOPEX05 (Ao et al., 2007). The results of the $\mathrm{CO}_{2}$ flux measurement over the Loess Plateau show that the diurnal cycle of $\mathrm{CO}_{2}$ flux is similar to the typical grassland with a maximal value $0.07 \mathrm{mg} / \mathrm{m}^{2} \mathrm{~s}$ in nighttime and minimal value $-0.22 \mathrm{mg} / \mathrm{m}^{2} \mathrm{~s}$ in daytime. 

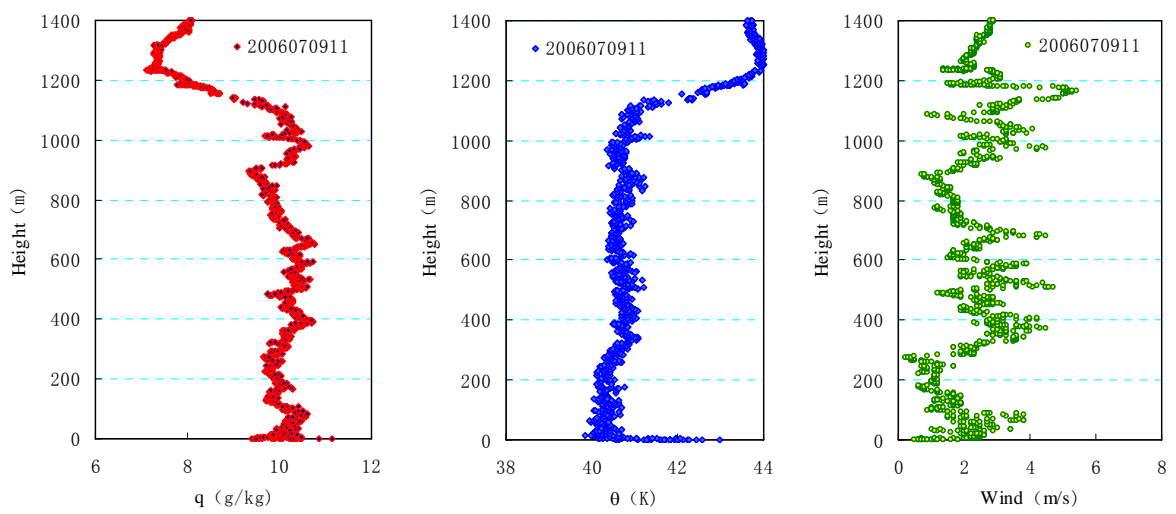

Fig. 4. The profile of potential temperature, moisture ratio and wind rate over the LOPEX study area sounded by the tether-balloon at 11:00 BT 9 September, 2006.

The potentials for estimating land surface evapotranspiration and vegetation water content by using remote sensing data from Medium Resolution Imaging Spectrometer (MERIS) and Advanced the Along-Track Scanning Radiometer (AATSR) were explored. The net radiation, sensible heat flux and soil heat flux were computed with consideration of the vegetation canopy and land surface characteristics. Comparison of the latent heat flux with ground observation collected from LOPEXs, the maximum and minimum errors of this approach were $11.0 \%$ and $4.8 \%$, respectively (Liu et al., 2008).

The maximal evapotranspiration of the cropped land surface was about $0.05 \mathrm{~mm} \mathrm{~h}^{-1}$ at noon (daily amount is about $0.30 \mathrm{~mm} \mathrm{day}^{-1}$ ) under the moderate soil water condition, and it could reach $4.60 \mathrm{~mm} \mathrm{day}^{-1}$ in the first cloud-free day after every rainfall events over the winter wheat field, and it was $3.70 \mathrm{~mm} \mathrm{day}^{-1}$ over bare soil land. From the last-ten days of April to middle-ten days of July in 2006, the water deficit of topsoil were $39.9 \mathrm{~mm} \mathrm{~m}^{-2}$ in winter wheat field and $17.9 \mathrm{~mm} \mathrm{~m}^{-2}$ and $25.3 \mathrm{~mm} \mathrm{~m}^{-2}$ in bare soil land. Due to the coming of raining season, the soil water began to be surplus in the first and middle-ten days of July. From the middle-ten days of July to the last ten-days of August in 2005, water surplus of topsoil was $17.90 \mathrm{~mm} \mathrm{~m}^{-2}$ in underlying surface with corn and $25.30 \mathrm{~mm} \mathrm{~m}^{-2}$ over bare soil land. Statistical results at the different time scales indicate that precipitation were the main impact factor for evapotranspiration and determinant factor for water deficit of the terrestrial topsoil in Loess Plateau land mesa region (Wang et al., 2009).

The LOPEXs and its database give prominence in the following aspects:

3.1 Intercrossing of the knowledge in different disciplines. The researchers involved in the LOPEXs have strong backgrounds in meteorology, hydrology, Ecology and satellite remote sensing.
3.2 Understanding of the Loess Plateau land surface process at temporal and regional scales, especially by using combinations of the ground measurements, satellite remote sensing and numerical simulation.

3.3 The distinct objectives of the field experiments. The research topics and contents of LOPEXs were carefully designed by the researchers prior to the experiments, and performed strictly according to the field experiment plan.

3.4 The LOPEX series started from 2004, has been carried out for 5 years, and will be continued in future years. Each year a new research topic will be addressed..

3.5 The broad openness of the LOPEXs database. All researchers interested in the Loess Plateau land surface process study are to use or cite the database once downloaded from the equipments.

3.6 Successful in training young researchers. LOPEXs has been training the participants in the techniques of field observation, numerical simulation and satellite remote sensing, and accumulated expertise for conducting researches in this area in the future.

\section{Final comments}

The LOPEX series were successful in collecting measurements data of the land surface energy fluxes, soil temperature and moisture, and near surface layer meteorological variables, vegetation leaf area index, vegetation water content, height and boundary-layer meteorology sounding datasets at temporal and spatial scale. The LOPEXs' database were widely used or cited by the researchers from Institute of Atmospheric Physics of Chinese Academy of Sciences, Cold and Arid Regions Environmental and Engineering Research 
Institute of Chinese Academy of Sciences, Lanzhou University, and Chinese Academy of Meteorology Sciences, International Institute for Geo-information Science and Earth Observation (ITC) of the Netherlands. These datasets can provide great support to analyze the characteristics of the loess plateau land surface process, improving and validating the satellite remote algorithm. This overview was prepared shortly after the LOPEX08, and therefore only reported on a very limited set of results. A more complete analysis about the LOPEXs datasets will come out later. In the next period, the LOPEXs project will focus on the following research objectives:

4.1 Land surface variables estimated from satellite remote sensing data over the Chinese Loess plateau mesa region;

4.2 Microwave remote sensing for soil moisture retrieval over the loess mesa region;

4.3 The regional distribution of surface temperature assessed from remote sensing over the Chinese Loess Plateau;

4.4 Mapping vegetation water content from satellite remote sensing over the Loess Plateau mesa;

4.5 Land surface energy balance assessment from remote sensing over the Chinese Loess Plateau mesa during crop growing season;

4.6 Characteristics of the land surface energy complements over the Loess Plateau;

4.7 Water deficit of the topsoil over the Chinese Loess Plateau mesa region;

4.8 Study on the surface energy storage terms at the Loess Plateau mesa cornfield;

4.9 Water and heat transferring within the loess soil;

4.10 Inter-comparison of the land surface process assessed from the eddy covariance flux systems and the boundary-layer meteorology tower;

4.11 Relationship between vegetation variation and climate change over the Chinese Loess Plateau;

4.12 The characteristics of meteorology boundary-layer Sounding over the Loess Plateau mesa region.

Other valuable research topics, which are not mentioned above are still welcome to be explored by using the datasets collected during the LOPEXs in the future.

Acknowledgements. Funding of the Centurial Program sponsored by the Chinese Academy of Sciences (2004406), the National Basic Research Program of China (Grant No. 2009CB421402) and the field station foundation of the Chinese Academy of Sciences,
Supports from the LOPEXs research team and the equipment and logistical support provided by Pingliang Lightning and Hail Storm Experiment Station of The Chinese Academy of Sciences made possible the success of the LOPEX field campaign.

Edited by: Z. Su

\section{References}

Ao, Y. H., Wen, J., and Lü, S. H.: A study of the water and energy transfer at the soil surface in cropped field on the Loess Plateau of northwestern China, Environ. Geol., 52, 595-603, 2007.

Gao, Z. Q., Lenschow, D. H, Horton, R., Zhou, M. Y., Wang, L. L., and Wen, J.: Comparison of two soil temperature algorithms for a bare ground site on the Loess Plateau in China, J. Geophys. Res., 113(D18), 18105, doi:10.1029/2008JD010285, 2008.

Liu, H. Z., Tu, G., Fu, C. B., and Shi, L. Q.: Three-year Variations of Water, Energy and CO2 Fluxes of Cropland and Degraded Grassland Surfaces in a Semi-arid Area of Northeastern China, Adv. Atmos. Sci., 25(6), 1009-1020, 2008.

Liu, R., Wen, J., Zhang, T. T., Liu, Y. Y., and Li, Zh. Ch.: Vegetation W ater Content Retrieved Using M ERIS and AATSR Data over the Loess Plateau Field Experiment 2005, Remote Sensing Technology and Appllcation, 22, 371-381, 2007 (in Chinese with English abstract).

Liu, R., Wen, J., Zhang, T. T., Liu, Y. Y., and Li, Zh. Ch.: A study on evapotranspiration retrieval using MERIS and AATSR data over the Loess Plateau mesa regions, Plateau Meteorology, 27, 949-955, 2008 (in Chinese with English abstract).

Liu, Y. Y., Wen, J., Wei, Z. G., Li, Zh. Ch., Zhang, T. T., and Liu, Y. Y.: Observation and Analysis of the Land Surface Radiation and Energy Balance over the Loess Plateau Mesa Region, Plateau Meteorology, 26, 928-937, 2007 (in Chinese with English abstract).

Ma, Y. M.: Remote sensing parameterization of regional land surface heat fluxes over and area in northwestern China, J. Arid Environ., 57, 257-273, 2004.

Meyers, T. P. and Hollinger, S. E.: An assessment of storage terms in the surface energy balance of maize and soybean, Agr. Forest. Meteorol., 125, 105-115, 2004.

Qian, L. Q:. Climate of the Chinese Loess Plateau, Meteorology Press, Beijing, China, 1991 (in Chinese).

Su, Z.: The Surface Energy Balance System (SEBS) for estimation of turbulent heat fluxes, Hydrol. Earth Syst. Sci., 6, 85-100, 2002 , http://www.hydrol-earth-syst-sci.net/6/85/2002/.

Vernekar, K. G., Sinha, S., Sadani, L. K., Sivaramakrishnan, S., Parasnis, S. S., Mohan, B., Dharmaraj, S., Patil, M. N., Pillai, J. S., Murthy, B. S., Debaje, S. B., and Bagavathsingh, A.: An overview of the land surface processes experiment (LASPEX) over a semi-arid region of India, Bound.-Lay. Meteorol., 106, 561-572, 2002.

Wang, X., Wen, J., Wei, Z. G., Tian, H., Wang, L., Li, Z. C., Shi, X. K., Zhang, T. T., Liu, R., and Zhang, J. H.: Study on Water Deficit of the Topsoil over the Chinese Loess Plateau Mesa Region, Plateau Meteorology, in press, 2009 (in Chinese with English abstract).

Wei, Z. G., Wen, J., Lü, Sh. H., Chen, Sh. Q., Ao, Y. H., and Yang, L.: The pilot experiment of land-atmosphere interaction 
and characters of land surface energy budget over the Loess Plateau, Plateau Meteorology, 24, 545-555, 2005 (in Chinese with English abstract).

Wei, Z. G. and Wen, J.: Vertical atmospheric structure of the late summer clear days over the east Gansu Loess Plateau in China, Adv. Atmos. Sci., 26(3), 381-389, 2009.

Wen, J., Su, Z. B, and Ma, Y. M.: Determination of land surface temperature and soil moisture from Tropical Rainfall Measuring Mission/Microwave Imager remote sensing data, J. Geophys. Res., 108(D2), 4038, doi:10.1029/2002JD002176, 2003.

Wen, J., Wei, Z. G., Lu, S. H., Ao, Y. H., and Liang, L.: The Characteristics of Land Surface Energy and Water Exchange over the Loess Plateau Mesa in China, Adv. Atmos. Sci., 24(2), 1-10, 2007.
Yang, X. G., Ma, P. L., Zhang, Q., Yang, Q. G., Wang, R., and Liu, H. Y.: Experimental study on surface energy balance over Loess Plateau of middle part Gansu in summer, Plateau Meteorology, 23, 828-834, 2004 (in Chinese with English abstract).

Yang, W. Z. and Shao, M. A.: Study of soil water on the Loess Plateau, Science Press, Beijing, China, 35-85, 2000.

Zhang, Z. H. and Liu, Y. X.: Nine Curved Yellow River and Long Ranged Sand: Yellow River and the Chinese Loess Plateau, Tsinghua University Press, Beijing, China, 2000 (in Chinese).

Zhang, T. T., Wen, J., Su, Z. B., Velde, R., Timmermans, J., Liu, R., Liu, Y. Y., and Li, Z. C.: Soil moisture mapping over the Chinese Loess Plateau using ENVISAT/ASAR data, Adv. Space Res., 43, 1111-1117, 2009. 